\title{
Erratum: Prediction of human population responses to toxic compounds by a collaborative competition
}

Federica Eduati, Lara M Mangravite, Tao Wang, Hao Tang, J Christopher Bare, Ruili Huang, Thea Norman, Mike Kellen, Michael P Menden, Jichen Yang, Xiaowei Zhan, Rui Zhong, Guanghua Xiao, Menghang Xia, Nour Abdo, Oksana Kosyk, the NIEHS-NCATS-UNC DREAM Toxicogenetics Collaboration, Stephen Friend, Allen Dearry, Anton Simeonov, Raymond R Tice, Ivan Rusyn, Fred A Wright, Gustavo Stolovitzky, Yang Xie, \& Julio Saez-Rodriguez

Nat. Biotechnol. 33, 933-940 (2015); published online 10 August 2015; corrected after print 1 October 2015

In the version of this article initially published, in the HTML only, all authors names were incorrectly included in the main author list, and several authors names were repeated. The authors have now added 12 additional authors to the list of "Other participants in the NIEHS-NCATS-UNC DREAM Toxicogenetics Collaboration," including Alok Jaiswal, Antti Poso, Himanshu Chheda, Ismeet Kaur, Jing Tang, John-Patrick Mpindi, Krister Wennerberg, Natalio Krasnogor, Samuel Kaski, Tero Aittokallio, Petteri Hintsanen and Suleiman Ali Khan. Names in this list that were also in the list of "top-performing teams" have been deleted. In addition, affiliation number 3 (Univ. Texas) has been added to Xiaowei Zhang's name in the main author list. The errors have been corrected in the HTML and PDF versions of the article.

\section{Erratum: Drug pipeline: 2Q15}

Laura DeFrancesco

Nat. Biotechnol. 33, 795 (2015); published online 7 August 2015; corrected after print 6 October 2015

In the version of this article initially published, in the "Notable clinical trial results (2Q 2015)" table, clinical trial data for the drug Glembatumumab vedotin was said to be phase 3. It was phase 2, not phase 3, data. The error has been corrected in the HTML and PDF versions of the article.

\section{Corrigendum: Assembling large genomes with single-molecule sequencing and locality-sensitive hashing}

Konstantin Berlin, Sergey Koren, Chen-Shan Chin, James P Drake, Jane M Landolin \& Adam M Phillippy

Nat. Biotechnol. 33, 623-630 (2015); published online 25 May 2015; corrected after print 6 October 2015

In the version of this article initially published, equation 9 appeared incorrectly as:

$$
f(x ; H, p)=1-\left[\left(\begin{array}{c}
H \\
x-1
\end{array}\right) p^{x-1}(1-p)^{H-x}\right]
$$

The equation has been corrected in the HTML and PDF versions of the article. 